\title{
Epithelial cells bearing class II molecules stimulate allogeneic human colonic intraepithelial lymphocytes
}

\author{
P Hoang, B Crotty, H R Dalton, D P Jewell
}

\begin{abstract}
HLA-DR+ gut epithelial cells may present antigen to intraepithelial lymphocytes (IEL). This study aimed to isolate an IEL population from the human colon to activate CD3+IEL by a human colonic epithelial cell line (HT-29), bearing different concentrations of class II antigen (HLA-DR). IEL were isolated by a mechanical method from six patients with ulcerative colitis (UC) and from 14 control patients. IEL were cocultured with HT-29 which had been induced to express class II molecules by $\gamma$-interferon (IFN- $\gamma$ ) in a dose dependent manner. The phenotype and the subsequent expression of activation markers by the IEL were determined to two colour flow cytometry. The IEL population had a CD4/ CD8 ratio similar to that seen in tissue sections. In the mixed cell culture, the degree of IEL activation showed a positive correlation with the degree of HLA-DR expression by the HT29 cells and the IEL secreted a IFN- $\gamma$ like factor that in turn stimulated the HT-29. Thus, depending on their expression of HLA molecules, colonic epithelial cells are able to activate $\mathrm{CD}^{+} \mathrm{CD8}^{+}$IEL

(Gut 1992; 33: 1089-1093)
\end{abstract}

The aetiology of ulcerative colitis remains unknown. However, within the inflamed mucosa there is an increase in plasma cells producing IgG or IgM, ' complement activation ${ }^{23}$ and activation of macrophages ${ }^{47}$ and lymphocytes. ${ }^{89}$ For the initiation of a specific immune response by helper $\mathrm{T}$ cells, antigen must be presented to them by a cell expressing major histocompatibility complex (MHC) class II proteins. Class II molecules are present on antigen presenting cells, dendritic cells, B cells, monocytes, and macrophages. The normal colonic epithelial cell does not express HLA-DR molecules unless it becomes inflamed. ${ }^{10-13}$ Thus, it is possible that colonic epithelial cells may function as antigen presenting cells once HLA$\mathrm{DR}$ is induced in an analogous way to thyrocytes. ${ }^{14} 15$ Therefore, it is possible that this increased antigen presentation could be responsible for inducing chronic disease as seen in patients with ulcerative colitis and Crohn's disease. However, since HLA-DR expression occurs in infective colitis, ${ }^{16}$ which can be selflimiting, other factor(s) must be involved.

Bland and Warren have shown that $\mathrm{Ia}^{+}$(class II) bearing columnar epithelial cells isolated from the rat small intestine can present protein antigen in vitro, inducing proliferation of primed T cells. ${ }^{17}$ This apparently class II restricted immune response led to antigen specific suppression..$^{18}$ In man, Mayer and Shlien were able to show that normal lightly fixed epithelial cells selectively stimulate peripheral blood lymphocytes of the suppressor/cytotoxic phenotype..$^{19}$ In contrast, epithelial cells from patients with Crohn's disease or ulcerative colitis stimulate T helper cells. ${ }^{20}$

Intraepithelial lymphocytes (IEL), because of their close spatial relation with epithelial cells and their unusual phenotype,$^{21-24}$ may be the cells responding in vivo to antigens presented by inflamed epithelial cells.

The aim of this study was to test the hypothesis that epithelial cells expressing class II molecules can activate allogeneic IEL and that, in ulcerative colitis, the function of IEL may be altered.

\section{Methods}

\section{PATIENT POPULATION}

Segments of resected colon were obtained from two groups of patients coming to surgery.

\section{Patients with ulcerative colitis}

These six subjects had a median age of 30 years (range 21 to 58 years): one was male and five female. All the patients had active disease at the time of surgery and were receiving corticosteroids. The tissue was taken from the least inflamed part of the colon.

\section{Control patients}

These 14 subjects had a median age of 65 years (range 25 to 77 years): six were male and eight female. Twelve patients had colonic carcinoma, one had intermittent volvulus, and one underwent colectomy for constipation. The specimens were taken at least $5 \mathrm{~cm}$ from any macroscopic lesion and were shown subsequently to be histologically normal.

The use of resected colon specimens for cell isolation studies has been approved by the Central Oxford Research and Ethics Committee.

\section{ISOLATION OF IEL}

Colonic specimens were immersed after resection in RPMI-1640 medium containing $2 \mathrm{mM}$ glutamine, $25 \mathrm{mM}$ Hepes (Gibco, Paisley, UK) supplemented with $10 \%$ fetal calf serum (Flow Laboratories, Irvine, UK), $50 \mu \mathrm{g}$ gentamicin $/ \mathrm{ml}$, and $100 \mathrm{U} / \mathrm{ml}$ penicillin (RPMI). The fat, blood vessels, and mesentery were removed. The specimen was washed vigorously
Correspondence to: Dr D P Jewell, Gastroenterology Unit, OX2 6HE.

Accepted for publication 9 December 1991
Gastroenterology Unit Oxford

B Crotty 
with Hank's balanced salt solution without calcium and magnesium (Flow Laboratories) and cut into small pieces of $2 \mathrm{~cm}^{2}$. The mucosal surface was then lightly scraped with a scalpel. The fragments were stirred in RPMI containing $1 \mathrm{mM}$ dithiothreitol (Sigma Chemical Company, St Louis, MO, USA). The epithelial cells and IEL were washed, resuspended in RPMI, and vortexed. After 30 minutes of sedimentation at room temperature (to remove debris and large clumps of cells) the supernatant was passed through a glass wool column (Sigma Chemical Company, St Louis, MO, USA) followed by centrifugation over a discontinuous Percoll gradient of 44 and $67 \cdot 5 \%$ (Sigma Chemical Company, St Louis, MO, USA). The IEL were collected at the interface.

\section{HUMAN COLONIC EPITHELIAL CELL LINE}

$10^{6}$ cells of the human colon cancer cell line, HT 29 were cultured at $37^{\circ} \mathrm{C}$ in $7 \mathrm{ml}$ Leibowitz medium (Gibco, Paisley, UK) with $10 \%$ fetal calf serum (FCS) (Flow Laboratories, Irvine, UK), 2 $\mathrm{mM}$ glutamine, $100 \mathrm{U} / \mathrm{ml}$ penicillin, and $50 \mu \mathrm{g} / \mathrm{ml}$ gentamicin (L-15) in $25 \mathrm{~cm}^{2}$ tissue culture flasks (Sterilin, Feltham, UK). After 24 hours, recombinant $\gamma$ interferon (IFN- $\gamma$ ) (a gift of Wellcome Biotech, Beckenham, UK) was added in concentrations up to $100 \mathrm{U} / \mathrm{ml}$ in fresh medium. After a further 48-72 hours, the cells were harvested by treatment with $0.2 \mathrm{mg} / \mathrm{ml}$ trypsin (Worthington Biochemical Corporation, Freehold, NJ, USA) and $10 \mathrm{mM}$ EDTA and washed four times in $\mathrm{L} 15$ without IFN- $\gamma$. Aliquots of $5 \times 10^{5}$ cells were transferred into Falcon polystyrene test tubes (Becton Dickinson, Lincoln Park, NJ, USA) for staining. $15 \times 10^{3}$ HT-29 cells expressing HLA-DR were resuspended in $500 \mu \mathrm{l} \mathrm{L}-15$ in 24 well plates (Limbro, Flow Laboratories, Rickmansworth, UK) for functional assays.

\section{COCULTURE EXPERIMENTS}

$3 \times 10^{5}$ IEL were cocultured with 15000 untreated or IFN- $\gamma$ treated HT-29 in 24 well plates. Total volume per well was $1 \mathrm{ml}$. HT-29 and lymphocytes were incubated for five days at $37^{\circ} \mathrm{C}$. The lymphocyte activation was determined by detecting the quantitative expression of IL-2 receptor, and HLA-DR, using two colour immunofluorescence and flow cytometry (FACScan, Becton Dickinson). Expression of activation markers was correlated with the degree of HLA-DR expression on the stimulating HT-29, also measured by flow cytometry. For each experiment an aliquot of IFN- $\gamma$ treated

TABLE I Monoclonal antibodies

\begin{tabular}{|c|c|c|}
\hline Monoclonal antibodies & $\begin{array}{l}\text { Cluster } \\
\text { designation }\end{array}$ & Specificity \\
\hline HLE-1 (FITC)/Leu-M3 (PE) & $\mathrm{CD} 45 / \mathrm{CD} 14$ & $\begin{array}{l}\text { A pan leukocyte and a human monocyte, } \\
\text { macrophage antigen }\end{array}$ \\
\hline $\begin{array}{l}\text { IgG1 (FITC)/IgG2 (PE) } \\
\text { Leu-3 (FITC)/Leu2a (PE) } \\
\text { Leu-4 (FITC)/HLA-DR (PE) } \\
\text { Leu-4 (FITC)/IL-2R (PE) } \\
\text { Leu-2 (FITC) } \\
\text { Leu-4 (FITC) } \\
\text { HLA-DR (PE) }\end{array}$ & $\begin{array}{l}\text { CD4/CD8 } \\
\text { CD3/- } \\
\text { CD3/CD25 } \\
\text { CD8 } \\
\text { CD3 } \\
-\end{array}$ & $\begin{array}{l}\text { Isotype-matched immunoglobulins, controls } \\
\text { CD4/CD8 ratio } \\
\text { MHC class II antigens found on activated T cells } \\
\text { Interleukin- } 2 \text { receptor found on activated T cells }\end{array}$ \\
\hline
\end{tabular}

HT-29 cells was incubated alone for five days. Table II shows that, in the absence of IEL, the HLA-DR expression fell during the culture period suggesting that there was no carry-over of IFN- $\gamma$.

\section{BLOCKING EXI'ERIMENTS}

The mouse anti-human MHC class I antigen monoclonal antibody W6/32 (a gift from Dr D Simmonsa, ICRF, John Radcliffe Hospital, Oxford) was used for blocking MHC class I antigen. The monoclonal antibodies 20-15-21, 16-27-12, and NFKZ (provided by Dr S Fuggle, Nuffield Department of Surgery, Oxford) were used in blocking MHC class II antigens. Before adding the IEL, the HT-29 were preincubated for 30 minutes with the various monoclonal antibodies (W6/32 at final dilution of $1 / 100$ and $1 / 200$ and the others at final dilution of $1 / 100$ ).

\section{IMMUNOFLUORESCENCE AND CELL STAINING}

The IEL were harvested by pipetting. The adherent HT-29 were detached as described above. After washing, aliquots $(50-100 \mu \mathrm{l})$ of IEL and HT-29 cells were incubated with the monoclonal antibodies $(10 \mu \mathrm{l})$ in the dark at $4^{\circ} \mathrm{C}$ for 30 minutes. Unbound antibody was removed with $2 \mathrm{ml}$ Dulbecco's phosphate buffered saline (PBS) without sodium bicarbonate, Gibco, Paisley, UK) with $0 \cdot 1 \%$ sodium azide (Sigma Chemical Company, St Louis, MO, USA). After centrifugation at $250 \mathrm{~g}$ for 5 minutes, the supernatant was discarded and the cells were fixed with $500 \mu \mathrm{l}$ of $1 \%$ paraformaldehyde (Sigma Chemical Company, St Louis, MO, USA) in PBS/azide. Flow cytometry and analysis of stained cells was performed on a FACScan (Becton Dickinson). Forward and side scatter gates were set on IEL and HT-29 cells to exclude other cells. Since the lymphocytes are much smaller than HT-29 cells, the gates set by forward scatter (which analyses cell size) clearly demarcated the two populations so that the degree of fluorescence by each cell population could be measured. Additional evidence that gating for cell size separated the two populations was obtained by staining for CD3.

MONOCLONAL ANTIBODIES

Five pairs of monoclonal antibodies and three

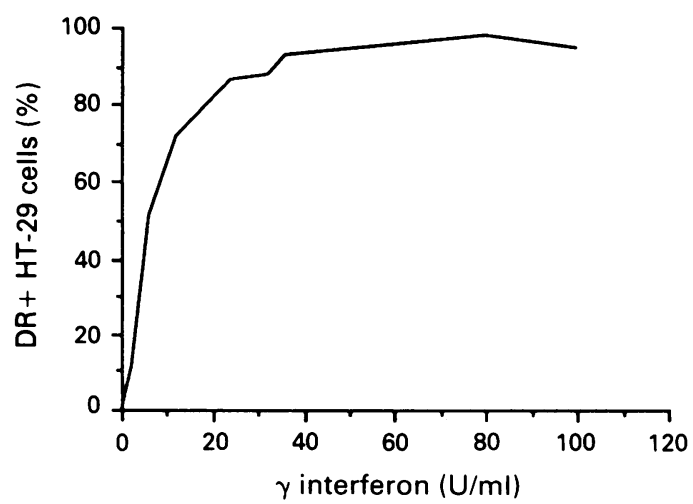

Figure 1: Induction of HLA-DR on HT-29 cells by $\gamma$ interferon. Percentage of cells expressing HLA-DR (y axis) after incubation with $\gamma$ interferon ( $x$ axis). 
Figure 2: $H L A-D R$ cultured with or without intraepithelial lymphocytes (IEL) from control or ulcerative colitis patients. $H T-29$ were cultured alone ( $\square$ ) or in the presence of IEL (А). expression on HT 29 cells

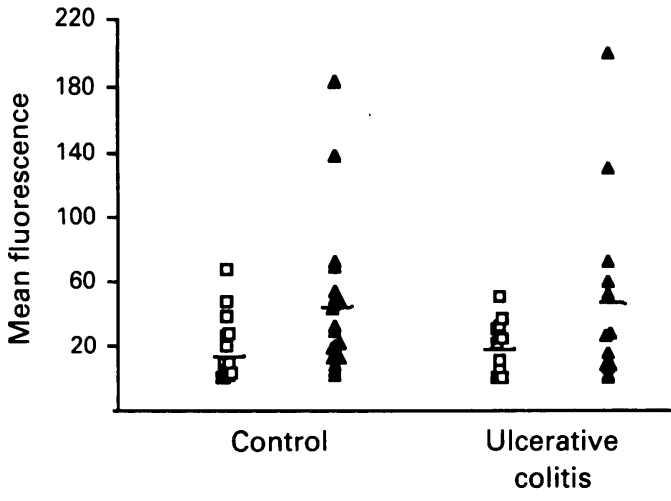

single reagents conjugated with fluorescein isothiocyanate (FITC) or phycoerythrin (PE) were used and are listed in Table I. All conjugated monoclonal antibodies were provided by Becton Dickinson Immunocytometry Systems (Mountain View, CA, USA).

\section{STATISTICS}

Grouped data were expressed as median and range. Differences between measurements were assessed by the Mann-Whitney $U$ test. The significance of correlation was determined by the Spearman rank correlation test. Statistical significance was taken as $\mathrm{p}<0.05$.

\section{Results}

PHENOTYPIC CHARACTERISATION OF IEL

The IEL suspensions (from ulcerative colitis and control patients) had median CD4:CD8 ratios of $0 \cdot 1$ (range $0 \cdot 1-0 \cdot 2$ ) and $0 \cdot 1$ (range $0 \cdot 1-0 \cdot 4$ ) respectively.

INDUCTION OF HLA-DR ON HT-29 CELLS BY IFN- $\gamma$ As previously described, ${ }^{2526}$ we found that unstimulated HT-29 cells did not express class II antigens and that recombinant IFN- $\gamma$ induced expression of HLA class II molecules in a dose dependent fashion with $100 \mathrm{U} / \mathrm{ml}$ as an optimal dose (Fig 1). The induction of HLA-DR antigens was assessed quantitatively by flow
Figure 3: Effects of increasing $H L A-D R$ expression on HT-29 cells. Percentage of HT29 expressing $H L A-D R(x$ axis). Percentage increase (above baseline) of intraepithelial lymphocytes from controls $(\square)$ and ulcerative colitis patients ) expressing $H L A-D R$ after incubation with $H T 29$ (y axis).

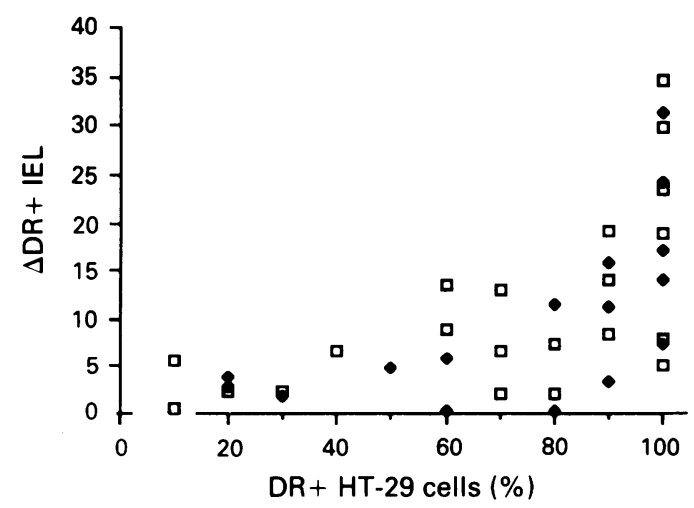

TABLE II Change in median HLA-DR expression on HT 29 cells (after incubation with $\gamma$ interferon) during subsequent culture without intraepithelial lymphocytes

\begin{tabular}{lccccc}
\hline \multicolumn{7}{c}{$H L A-D R$} & expression $(\%)$ \\
\hline Day 0 (n=) & $10(2)$ & $40(1)$ & $70(3)$ & $90(3)$ & $100(6)$ \\
Day 5 (range) & $3(3-3)$ & 3 & $5(12-17)$ & $15(10-35)$ & $30(25-40)$ \\
\hline
\end{tabular}

cytometry before and after coculture with IEL. During culture with IEL, the percentage of HT-29 cells bearing HLA-DR remained approximately the same but the density of HLADR on those cells expressing these molecules increased. Fig 2 shows that, especially for ulcerative colitis, the mean fluorescence (that is, density of HLA-DR) increased during the coculture. In contrast, the percentage of DR expression on HT-29 cells cultured without IEL fell considerably (Table II).

\section{ACTIVATION OF IEL SUBSETS BY HT-29 CELLS}

The proportion of gated IEL expressing IL2-R and HLA-DR was quantitated. For control patients, $14.8(9.3) \%$ of IEL expressed HLADR compared with $28.0(13.7) \%$ of IEL in patients with ulcerative colitis. In mixed cell cultures there was a significant correlation between HLA-DR expression on the HT-29 cells and the activation of $\mathrm{CD}^{+}{ }^{+}$IEL as determined by DR expression (controls $r=0.739$, $\mathrm{p}=0.001$, ulcerative colitis $\mathrm{r}=0.633, \mathrm{p}=0.002$ ) (Fig 3), although the correlation with IL2-R was not significant. There was no significant difference in HT29 induced expression between IEL from controls or patients with ulcerative colitis. For the $\mathrm{CD}^{+}$IEL subset, there was also a significant correlation between DR expression during culture and the DR expression on the HT-29 cells (controls $r=0.667, p=0.009$, ulcerative colitis $r=0.727, p=0.009)$. For $\mathrm{CD}^{+}$IEL this correlation was not significant for either the control patients or those with ulcerative colitis. However, there were only a limited number of $\mathrm{CD} 4^{+}$IEL.

\section{BLOCKING EXPERIMENTS}

Anti-human MHC class II monoclonal antibody inhibited the activation of $\mathrm{CD}^{+}$IEL by IFN- $\gamma$ induced HT-29. The $\%$ inhibition was calculated by the formula:

$$
1-\frac{A-B}{C-B} \times 100
$$

where: $A=\%$ IEL $D^{+}$incubated with blocking antibody and stimulated HT-29; $B=\%$ IEL $\mathrm{DR}^{+}$incubated with unstimulated $\mathrm{HT}-29 ; \mathrm{C}=$ $\%$ IEL $\mathrm{DR}^{+}$incubated with stimulated $\mathrm{H}-29$.

The three antibodies to class II MHC antigens showed differences in the degree of inhibition of HLA-DR activation. Antibody 20-15-21 resulted in $80-100 \%$ inhibition, NFKZ 35-80\%, and $16-27-21$ in only $0-40 \%$. Similar degrees of inhibition occurred whether $\mathrm{CD}^{+}$or $\mathrm{CD}^{+}$cells were analysed. Antibody to class I molecules showed no inhibition of IEL activation and indeed, in some experiments activation was increased (data not shown).

\section{Discussion}

We have confirmed that a class II expressing colonic cancer cell line HT-29 activates IEL and might therefore behave as an antigen presenting cell. Mayer and Schlien have already provided some evidence that such a mechanism can occur using human peripheral blood cells as responder 
cells $^{1920}$ and Bland et al have also found a similar regulatory role for epithelial cells in rats. ${ }^{17}{ }^{18}$ Both rats and human enterocytes can act as stimulators in an allogeneic mixed lymphocyte type response and these alloresponses can be blocked with anti-class II antibodies. ${ }^{18} 27$ However, IEL differ phenotypically and functionally from peripheral blood mononuclear cells $\mathrm{s}^{22-24}$ and their activation by IFN- $\gamma$ treated epithelial cells has not so far been shown.

HT-29 cells have been used in this study because human colonic epithelial cells do not survive long enough in culture to allow in vitro induction of class II molecules and paraformaldehyde fixation as used by Mayer and Schlien ${ }^{19} 20$ might impair antigen presentation or processing. Nevertheless, it is recognised that a cell line may have its own limitations. The activation of IEL was measured quantitatively using the expression of HLA-DR and IL-2R on the lymphocyte surface. ${ }^{3} \mathrm{H}$-thymidine incorporation, the usual assay for lymphocyte proliferation could not be used because (1) IEL proliferate poorly ${ }^{28}$ (a recent report suggests, however, that that can be overcome by an anti-CD2 molecule) ${ }^{24}$; (2) HT-29 cells proliferate even when irradiated or mitomicin-treated; and (3) HT-29 cells produce a soluble factor that blocks mitogen induced $\mathrm{T}$ cell proliferation, although expression of activation markers is unimpaired. ${ }^{29}$ The activation of IEL was not due to macrophages contaminating the coculture since the percentage of cells expressing LEU-M3 was less than 3\%.

Constitutive expression of HLA-DR molecules is restricted to cells of the immune system. Presentation of antigens to $\mathrm{T}$ lymphocytes by class II molecules is important in the initiation of an immune response. In pathological circumstances, expression also occurs on cells of the thyroid,,$^{14}$ skin, ${ }^{30}$ bile duct, ${ }^{31}$ and colon. ${ }^{16}$ It has been proposed that aberrant expression of class II molecules might allow presentation of autoantigens and hence initiate autoimmune destruction of the tissue. However, in human colon, HLA-DR expression occurs in infective colitis. ${ }^{16}$ Since this often resolves without therapy, other factors must be involved to explain the immunopathogenesis of the chronic inflammatory lesion of ulcerative colitis and Crohn's disease.

One hypothesis would be a defect in the regulation of the local immune response but so far there is little evidence that T cell, B cell, or macrophage function within the inflamed lamina propria is inappropriate to the degree of the inflammation. For the IEL compartment, there is no difference in phenotypic distribution in inflammatory bowel disease (Hoang $P$ and Jewell DP, unpublished observations), and we have been unable to demonstrate a suppressor defect in IEL isolated from inflammatory bowel disease patients compared with control IEL. ${ }^{32}$ Another possibility is an altered interaction between epithelial cells and T cells. Mayer has shown that in contrast to normal epithelial cells which stimulate $\mathrm{CD}^{+}$peripheral blood lymphocytes, epithelial cells from patients with Crohn's disease or ulcerative colitis, but not from other inflammatory disease, present antigen to $\mathrm{CD} 4^{+}$ peripheral blood lymphocytes. ${ }^{20}$ Of relevance, is the observation that a murine epithelial cell is able to present a soluble antigen to a specific class II restricted $\mathrm{L} 3 \mathrm{~T} 4^{+} \mathrm{T}$ cell hybridoma. ${ }^{33}$

This study has not tested Mayer's hypothesis that epithelial cells from inflammatory bowel disease patients activate $\mathrm{CD}^{+}{ }^{+}$lymphocytes as opposed to $\mathrm{CD}^{+}$cells. However, IEL from ulcerative colitis patients can be activated to a similar degree to IEL from controls using HT-29 epithelial cells, and activation was seen in both $\mathrm{CD}^{+}$and $\mathrm{CD} 4^{+}$subsets.

In conclusion, IFN- $\gamma$ treated HT-29 are able to stimulate allogeneic IEL in proportion to their expression of HLA class II molecules. This observation is compatible with the hypothesis that epithelial cells are able to function as accessory cells for an immune response. This may be important in ulcerative colitis and Crohn's disease when epithelial cells strongly express class II molecules.

P Hoang was supported by grants from The National Association for Crohn's and Colitis, and the Lee-Placito Medical Fund. We thank our surgeons, $\mathrm{Mr} M$ Kettlewell and $\mathrm{Mr} \mathrm{N}$ Mortensen, for providing colonic specimens.

Some of these data have previously been published in abstract Some of these data have previously
form (Gastroenterology 1990; 98: A455).

1 Brandtzaeg P, Halstensen TS, Kett K, Krajci P, Kvale D, Rognum TO, et al. Immunobiology and immunopathology of human gut mucosa: humoral immunity and intraepithelial lymphocytes. Gastroenterology 1989; 97: 1562-84.

2 Halstensen TS, Mollnes TE, Fausa O, Brandtzaeg P. Deposits of terminal complement complex (TCC) in muscularis mucosae and submucosal vessels in ulcerative colitis and mucosae and submucosal vessels in ulcerative coli
Crohn's disease of the colon. Gut 1989; 30: 361-6.

3 Halstensen TS, Mollnes TE, Brandtzaeg P. Persistent complement activation in submucosal vessels of active inflammatory bowel disease: immunohistochemical evidence. Gastroenterology 1989; 97: 10-9.

4 Gioncetti P, Mahida YR, Patel S, Jewell DP. Macrophage and lymphocyte subpopulations in magnifying endoscopic
lesions of Crohn's disease. Clin Exp Immunol 1988; 72: lesions

5 Mahida YR, Patel S, Wu KC, Jewell DP. Interleukin 2 receptor expression by macrophages in inflammatory bowe disease. Clin Exp Immunol 1988; 74: 382-6.

6 Mahida YR, Wu KC, Jewell DP. Enhanced production of interleukin $1-\beta$ by mononuclear cells isolated from mucosa with active ulcerative colitis or Crohn's disease. Gut 1989; 6 : 835-8.

7 Mee AS, Szawatakowski M, Jewell DP. Monocytes in inflammatory bowel disease: phagocytosis and intracellular killing f Clin Pathol 1980; 33: $921-5$.

8 Selby WS, Janossy G, Bofill M, Jewell DP. Intestinal lymphocyte subpopulations in inflammatory bowel disease: an analysis by immunohistological and cell isolation techanalysis by immunohistologic
niques. Gut $1984 ; 25: 32-40$.

9 Trejdosiewicz LK, Bard-El-Din S, Smart CJ, Malizia G, Oakes DJ, Heatley RV, et al. Colonic mucosal T lymphocytes in ulcerative colitis: expression of CD7 antigen in relation to MHC class II (HLA-D) antigens. Dig Dis $\mathrm{Sci}$ 1989; 34: 1449-56.

10 Hirata I, Austin LL, Blackwell WH, Weber JR, Dobbins III WO. Immunoelectron microscopic localization of HLA-DR antigen in control small intestine and colon and in inflammatory bowel disease. Dig Dis Sci 1986; 31: 1317-30.

11 Fais S, Pallone F, Squarcia O, Biancone L, Ricci F, Paoluzzi $\mathrm{P}$, et al. HLA-DR antigens on colonic epithelial cells in inflammatory bowel disease: I. Relation to the state of inflammatory bowel disease: I. Relation to the state of
activation of lamina propria lymphocytes and to the activation of lamina propria lymphocytes and to the
epithelial expression of other surface markers. Clin Exp Immunol 1987; 68: 605-12.

12 Selby WS, Janossy G, Mason DY, Jewell DP. Expression of HLA-DR antigens by colonic epithelium in inflammatory bowel disease. Clin Exp Immunol 1983; 53:61+8

13 Spencer J, Finn T, Isaacson PG. Expression of HLA-DR antigens on epithelium associated with lymphoid tissue in the human gastrointestinal tract. Gut 1986; 27: 153-7.

14 Loebenstein BG, Londei M, Greenall C, Pirich K, Kassal H, Waidhaüsl W, et al. Pathogenetic relevance of HLA class II expressing thyroid follicular cells in nontoxic goiter and in Graves' disease. $\mathcal{F}$ Clin Invest 1988; 81: 1608-14.

15 Feldmann M. Molecular mechanisms involved in human autoimmune diseases: relevance of chronic antigen presentaautoimmune diseases: relevance of chronic antigen presenta-
tion. Class II expression and cytokine production. Immunologv 1989; 2: 66-71.

16 McDonald GB, Jewell DP. Class II antigen (HLA-DR expression by intestinal epithelial cells in inflammatory diseases of colon. F Clin Pathol 1987; 40: 312-7.

17 Bland PW, Warren LG. Antigen presentation by epithelial cells of the rat small intestine. I. Kinetics, antigen specificity and blocking by anti-Ia antisera. Immunologi 1986; 58: 1-7.

18 Bland PW, Warren LG. Antigen presentation by epithelial cells of the rat small intestine. II. Selective induction of suppressor T cells. Immunologv 1986; 58: 9-14. 
19 Mayer LL, Shlien R. Evidence for function of Ia molecules on gut epithelial cells in man. $\mathcal{F}$ Exp Med 1987; 166: 1471-83.

20 Mayer LL, Eisenhardt D. Lack of induction of suppressor T cells by intestinal epithelial cells from patients with inflammatory bowel disease. 7 Clin Invest 1990; 86: 1255-60.

21 Dobbins WO. Progress report. Human intestinal intraepithelial lymphocytes. Gut 1986; 27: 972-85.

22 Selby WS, Janossy G, Jewell DP. Immunohistological characterisation of intraepithelial lymphocytes of the human gastrointestinal tract. Gut 1981; 22: 169-76.

23 Mowat AMcI. Human intraepithelial lymphocytes. Springer Semin Immunopathol $1990 ; 12$ : 165-90.

24 Ebert EC. Proliferative responses of human intraepithelial lymphocytes to various T-cell stimuli. Gastroenterology 1989 97: 1372-81.

25 Sollid LM, Brandtzaeg P, Kvale D, Gaudernack G, Scott H, Thorsby E. T cell-epithelium interactions in relation to gut immunity. Monogr Allergy 1988; 24: 60-5.

26 Lowes JR, Radwan P, Priddle JD, Jewell DP. Induction of HLA-DR molecules on a colonic epithelial cell line by $\gamma$ interferon. Clin Sci 1988; 74 (suppl 18): 31 P.

27 Bland PW. Syngeneic and allogenic T cell reactivity to I-region determinants on rat intestinal epithelial cells. Adv Exp Med Biol 1987; 216: 227-32.

28 Geenwood JH, Austin LL, Dobbins WO. In vitro characterisation of human intestinal intraepithelial lymphocytes. Gastroenterology 1983; 85: 1023

29 Ebert EC, Roberts AI, O'Connell SM, Robertson FM, Nagase H. Characterization of an immunosuppressive factor derived from colon cancer cells. $\mathcal{F}$ Immunol 1987; 138: 2161-8.

30 Gottlieb AB, Lifshitz B, Fu SM, Staiano-Coico L, Wang CY, Carter DM. Expression of HLA-DR molecules by keratinocytes, and presence of Langherhans cells in the derma infiltrate of active psoriatic plaques. $\mathcal{F} \operatorname{Exp}$ Med 1986; 164 1013-28.

31 Van den Oord JJ, Sciot R, Desmet VJ. Expression of MHC products by normal and abnormal bile duct epithelium. fHepatol 1986; 3: 310-7.

32 Hoang $P$, Dalton HR, Jewell DP. Human colonic intraepithelial lymphocytes are suppressor cells. Clin Exp Immunol 85: 498-503.

33 Kaiserlian D, Vidal K, Revillard JP. Murine enterocytes can present soluble antigen to specific Class II-restricted CD4 T cells. Eur F Immunol 1989; 19: 1513-6. 